\title{
E quando não houver ruínas?
}

\section{What If There Are No Ruins?}

\author{
Roberto Robalinho \\ Universidade Federal Fluminense, Niterói, Rio de Janeiro / Brasil \\ rrobalinho78@gmail.com
}

Resumo: Em junho de 2013 as ruas do Brasil foram tomadas por manifestantes. Se os protestos surpreendem e desestabilizam a realidade social com novas formas de ação política, esses processos tomam corpo através de uma relação contígua e simultânea com as imagens. Como podemos olhar para a relação liminar entre a multidão nas ruas e as telas para acessar a produção política e subjetiva de junho de 2013? Benjamin propõe um olhar sobre a história que não seja descritivo, linear e triunfalista, mas lacunar, sintomático, disruptivo, intensificado e capaz de atualizar as forças políticas no presente. Mais do que olhar o passado, Benjamin deseja intervir no presente. É a partir dessa provocação que olhamos as imagens de junho de 2013, mais especificamente para uma série de planos sequência que foram produzidos durante a noite de 17 de julho de 2013 quando o Bairro do Leblon foi tomado por manifestantes e barricadas em chamas. Porque o plano sequência e de que forma esta unidade de linguagem cinematográfica incorpora uma experiência das ruas insurgentes?

Palavras-chaves: junho de 2013; imagem; história; produção política; produção subjetiva; plano sequência

Abstract: In June 2013 Brazilian streets were overtaken by protests. If new forms of
political action capable of disrupting social reality were invented, this process was
lived through a contiguous and simultaneous relation with images. How can we access
June's 2013 political and subjective production through the liminal relation between
its images and the crowd on the streets? Benjamin proposes an approach to history that
is not explanatory, linear and triumphant, on the contrary is fragmented, symptomatic,
disruptive, intensified and able to bring forth political forces in the present. More than 
looking at the past, Benjamin desires to intervene in the present. This is a starting point to look at June 2013 images, more specifically, to a series of long shots that were produced in 2013 during the night of the 17 of July when the posh neighborhood of Leblon was overwhelmed by protesters and blazing barricades. Why the use of long shots and how does this unity of cinematic discourse express an experience of the insurgent streets?

Keywords: June 2013; image; history; political production; subjective production; long shot.

Recebido em: 30 de outubro de 2017.

Aprovado em: 6 de fevereiro de 2018.

Em junho de 2013, sem que ninguém pudesse prever, as ruas do Brasil se incendiaram. Manifestações contra o aumento das passagens no transporte público ocuparam diariamente as grandes capitais do Brasil. $\mathrm{O}$ que começou com centenas de manifestantes rapidamente se expandiu em milhares explodindo em múltiplos desejos e pautas. Ver aqueles jovens ali pulsando trazia a memória de acontecimentos recentes em outros lugares, como se as ruas do Brasil ressuscitassem as agitações da Primavera Árabe, do 15M na Espanha e dos Occupies. Sentíamos que a luta que se formava era muito maior do que o aumento das passagens, que havia ali uma explosão que não conseguíamos dimensionar, mas que provocava aberturas no corpo mesmo das cidades.

Para muitos que participaram ativamente dos protestos foi evidente que sua vivência se dava a partir de duas instâncias: uma carnal nas ruas e outra através de inúmeras imagens compartilhadas nas redes. A experiência do que era estar nos protestos se constituía neste ir e vir entre as ruas e as telas. Era comum ao voltar de uma manifestação se sentar na frente do computador e vivenciar uma série de imagens que estabeleciam uma colagem do que havia acontecido - o que expandia a própria experiência das ruas. Por outro lado, não havia hipótese de voltar às ruas sem que as imagens reverberassem durante o ato, sem que se notasse as inúmeras câmeras e performances, de que aquela forma de protestar era liminar ocupando esta fronteira entre mundo e imagens. Sem contar que várias disputas dos sentidos das manifestações, seja pela mídia tradicional ou pela mídia ativista, se dava também no campo das imagens. Surgia, portanto, um primeiro problema, havia uma relação 
inexorável entre um fazer político e a produção e circulação de imagens, de modo que - as ruas produziam imagens que produziam ruas que produziam imagens.

Ficou claro também que estávamos diante de outra forma de fazer política, muito diferente de outros momentos da história do Brasil em que o povo tomou as ruas como no Fora Collor, nos movimentos pelas Diretas Já e nas greves do ABC, para citar acontecimentos não tão distantes no tempo. Não havia líderes, nem instituições políticas como sindicatos e partidos organizando e pautando as ruas, pelo contrário, pautas e trajetos eram decididos no calor da hora e a todo momento havia o risco de explosões, de caminhos e atos inesperados. Não havia negociação possível a não ser revogar o aumento. As formas tradicionais de ação política eram contestadas abrindo fissuras nas possibilidades efetivas de uma democracia representativa mudar o mundo. Um grito constante da multidão era o - vocês não me representam. Ficava evidente que a representação política não comportava tantos desejos.

Mas, o que fizeram os manifestantes? Onde chegaram? Qual a efetividade política da multidão nas ruas? Não há uma solução simples para essas perguntas, ainda mais se pensarmos que os protestos produziram uma quebra na realidade política nacional apontando os limites de nosso sistema político e por outro lado não incorporaram uma nova e efetiva instituição política. Diria que, de certa forma, as fissuras abertas durante os protestos não se fecham e produzem um risco político, uma possibilidade de transformação, mas também de captura. Junho propõe uma pergunta que não se fecha por completo, como aponta Palbert,

Em nosso caso, não paramos de nos perguntar: mas afinal, o que queriam os que saíram às ruas em 2013? Mais saúde, educação, serviços, menos corrupção, mais transparência, uma reforma do sistema político? Ou tudo isso, claro, e algo ainda mais radical: um outro modo de pensar a própria relação entre o tempo da vida e da política? (PALBERT, 2015, p.168)

Um caminho para pensar a produção política dos protestos de junho de 2013 é olhar não para onde se chegou, mas para os processos engendrados durante o acontecimento e para as invenções políticas e subjetivas que se configuraram nas ruas. Mas, como olhar aquilo que se produziu uma vez que não estamos mais em junho? Haveria sobras, 
reminiscências ou ruínas onde poderíamos ainda vislumbrar as potências políticas de junho? Uma vez que há uma relação liminar entre a ação política nas ruas e a produção e circulação de imagens, no sentido em que a experiência dos protestos se constitui neste espaço entre as telas e as ruas, talvez, se há alguma sobra, ela se expresse neste agenciamento entre imagens e protesto.

Partindo da provocação de Benjamin (2008) em relação à história, tão bem elaborada por Gagnebin, "O que é contar uma história? O que é contar a História? (1992:2), como podemos lançar um olhar sobre essas imagens não como descrição dos conflitos da multidão nas ruas, mas como atualização de seus processos políticos e das fissuras provocadas na realidade social durante o acontecimento? $\mathrm{O}$ foco desse artigo, portanto, será pensar a partir de alguns pontos das já consagradas teses Sobre o conceito de história de Benjamin (2008), tensionados a partir de como as imagens agenciam uma produção política dos protestos de Junho de 2013. Para isso iremos nos concentrar na noite do dia 17 de julho no Rio de Janeiro quando uma manifestação na frente da casa do então governador Sérgio Cabral se espalhou pelas ruas do Leblon.

$\mathrm{O}$ cartaz de um manifestante que pode ser visto em fotografia tirada pela Midía NINJA ${ }^{1}$ descreve bem esta noite no Leblon, nele podemos ler: "a barricada fecha a rua para abrir novos caminhos". O bairro foi todo tomado por manifestantes e barricadas em chamas. Houve um corte radical no fluxo usual do bairro e, se por um lado carros e ônibus são impedidos de trafegar, manifestantes, transeuntes, moradores, qualquer um - passa a circular livremente pelas ruas. Em certo sentido, as ruas em chamas se tornam ruas em festa. Ranciere (2016) já nos alertava que a barricada é um rearranjo da ordem sensível da cidade - "Antes de ser uma tática militar, a barricada foi uma desordem de lugares e seus usos." (2016, p. 66). ${ }^{2}$ Pode-se dizer que naquela noite do Leblon propôs-se outro tempo - o tempo morto do tráfego - para outra circulação ser possível com o - tempo vivo dos corpos.

\footnotetext{
${ }^{1}$ Disponível em: $<$ https://www.facebook.com/MidiaNINJA/photos/a.164308700393950. 1073741828.164188247072662/205134272978059/?type=3\&theater $>$. Acesso em: out. 2017.

${ }^{2}$ Tradução livre de "Before becoming a military tactic, the barricade was a disorder of places and of their use." (RANCIÈRE, 2016, p. 66)
} 


\section{Narrar à contrapelo}

De que forma, as teses Sobre o conceito de história do Benjamin (2008) nos ajudam a pensar a relação entre produção política e a produção e circulação de imagens de junho de 2013 e o que se produziu de político na noite de protestos no Leblon? De imediato é preciso marcar a distância da experiência de olhar estas imagens contemporâneas de junho para uma experiência moderna presente neste texto escrito em 1939 por um intelectual que fugia do fascismo. Uma diferença fundamental, em termos de experiência e portanto também de uma estética (aesthesis), é que estas imagens de junho não tratam de impossibilidades ou de perdas, tão presentes no texto Benjaminiano - "a perda da tradição, a perda da narração clássica, a perda da aura etc..." (GANGNEBIN, 1999, p. 2). A princípio, nada mais distante destas imagens do que uma ideia de ruínas. Pelo contrário, aqui há explosão de possibilidades e produção política, ao invés de perdas, podemos falar de quebras: quebra de uma realidade política, quebra da representação e quebra de uma temporalidade linear vigente. Nos interessa em Benjamin, um pensamento crítico sobre a história, sobre o ofício de contar a história, sobre como contar a história pode ser um gesto de ruptura e sublevação que se aproxima do gesto político que esta análise gostaria de incorporar.

De imediato, Benjamin nos alerta para o fato de que para combater a "tempestade do progresso" (2008, p. 226), o fascismo, não se trata apenas de contar uma outra história, mas de como contar a história. Uma abordagem crítica da história é indissociável da sua forma narrativa, logo pensar a história, é elaborar outra forma narrativa, que não deixa de ser outra forma de experimentar e relatar o presente. Se há ruptura na ação das ruas, se há invenções e outras experiências temporais sendo engendradas, os relatos e os narrares sobre junho devem incorporar estas interrupções na sua forma. Vale a pena retomar dois pontos abordados por Benjamin (2008) para pensar a constituição desse novo narrar da história.

O primeiro é a imagem clássica a partir do gesto de "escovar a história a contrapelo" (BENJAMIN, 2008, p. 224) que seria uma forma de se opor a um contar triunfalista e progressista de um "historicismo" que nega a violência do processo histórico e a relação intrínseca entre barbárie e cultura. Contar a história a contrapelo é entender que não se pode conhecer um acontecimento por completo, que não há uma explicação da história, mas uma forma de compor com uma experiência 
da história, com algum resto, pedaço que ainda "relampeja" no presente - alguma fagulha a ponto de acender. Nesse sentido, produzir um relato da história deve ser também um gesto de revolta, um gesto de luta contra o status quo - um sopro na brasa quente.

O segundo é opor o "tempo homogêneo e vazio" da história a um tempo "saturado de agoras" (BENJAMIN, 2008, p. 229). Trata-se de pensar um tempo, uma forma narrativa, que combata o tempo regular de um historicismo e historiografia iluminista que, como nos descreve Gagnebin, é "(...) esse tempo indiferente e infinito que corre, sempre igual a si mesmo, que passa engolfando o sofrimento, o horror, mas também o êxtase e a felicidade." (1999, p. 96). Uma história que opera a partir da lógica da causa e efeito como se houvesse um único caminho natural e o papel do historiador fosse decifrar as causas que nos trazem ao presente e, por sua vez, quais seriam os efeitos que se projetam no futuro.

$\mathrm{O}$ "tempo de agora" seria aquele capaz de "explodir o continuum da história" (BENJAMIN, 2008, p. 230), típico de uma temporalidade revolucionária que inaugura um novo tempo, uma nova história a partir de um instante, um agora, intensificado, capaz de trazer a tona os vencidos de outrora, de fazer do passado, do e no presente, uma "experiência única" (2008, p. 231). Benjamin aposta na ação de um presente intensificado em conjunto com um olhar sobre o passado, sobre alguma sobra de um passado, para compor uma nova história que é uma forma de reescrever o presente.

A tarefa do historiador seria a de instaurar um novo tempo, "um tempo saturado de agoras" como forma de intervir no presente. Mas, e quando o próprio acontecimento se constitui como a experiência de um presente intensificado? Afinal, em junho de 2013, enquanto os corpos ardiam nas ruas, suas imagens circulavam nas redes por múltiplas câmeras e telas através de relatos simultâneos, convergentes e sobrepostos na natureza acumulativa do dispositivo das redes. Se, na noite de 17 de julho, manifestantes tomam as ruas do Leblon e suspendem o tempo regular da cidade, as imagens agenciam a intensificação dessa suspensão. Não poderíamos, no contexto da noite de protestos no Leblon, falar da explosão de um continuum da cidade? Seria possível, em termos estéticos e a partir de Benjamin (2008), pensar esta medida de intensidades, de sobreposição de "presentes" e de "rupturas", como forma de atualizar a abertura do gesto incendiário inicial das ruas em novas aberturas? 


\section{Olhar o fogo}

Safatle em seu manifesto sobre junho de 2013, Quando as ruas ainda queimam, nos diz que é preciso olhar as chamas para compreender o que aconteceu, afinal - "Quem ouvir o fogo queimar nas ruas perceberá que ele diz sempre a mesma coisa: que o tempo acabou." (2016, p.5). Dizer que o "tempo acabou" é desdobrar o tempo insurgente em três instâncias, a primeira é a do desejo que diz basta, nossas vidas e cidades podem ser outras, um grito que encerra o tempo vigente para convocar um tempo de agora. A segunda é apontar para outra experiência temporal inaugurada pelos corpos nas ruas, pelas suspensão do tempo provocada pelas barricadas. E uma terceira, é a necessidade de produzir um relato desse novo tempo, da possibilidade de sua incorporação estética em um outro narrar.

Seguindo a provocação de Safatle (2016), devemos encarar o fogo. No dia mesmo dos protestos no Leblon, um vídeo foi postado no youtube, não há nenhuma palavra na sua descrição, apenas o título que não ao acaso é: Leblon em chamas. ${ }^{3}$ Nele, uma câmera flutua por uma rua do Leblon, ela está um pouco acima da altura do olho e faz um travelling frontal seguindo pela rua. Ao longo do vídeo dois fenômenos mobilizam a imagem, o fogo e o tempo. Durante o percurso, em muitas das barricadas em chamas, a câmera faz uma leve panorâmica para que o fogo permaneça por mais tempo em quadro. Por outro lado, a duração do plano, nesse trajeto que parece não terminar, uma vez que a rua e as barricadas seguem, permite a repetição do fogo e sua extensão espacial pelo bairro. A intensidade das chamas, como da extensão do percurso, necessita não só do deslocamento da câmera, mas do plano sequência, da duração do plano. A imagem deseja esse mundo que arde. Há um inegável encontro entre as chamas e a câmera que produz a tensão desse plano.

No dia seguinte aos protestos e à postagem dessa imagem no youtube, Eduardo Escorel publicou em sua coluna digital Questões Cinematográficas na revista Piauí um link desse vídeo onde afirma "Vale a pena ver o plano gravado quarta feira à noite, no Leblon. Nesse travelling, terrível e belo, há uma rara conjugação de talento estético e virtuosismo documental." Escorel conecta a experiência estética do

\footnotetext{
${ }^{3}$ Disponível em: $<$ https://www.youtube.com/watch? $\mathrm{v}=$ WEHzAhB6j_w $>$.Acesso em: out. 2017:
} 
cinema à essa imagem do protesto. Porque o cinema aparece? Porque o cinema documental que traz um forte referente de real? Ao que devíamos também adicionar, porque o plano sequência que aponta para o mundo e para o tempo?

Se há, na experiência dos protestos do Leblon, através da ocupação das ruas por múltiplos corpos manifestantes uma suspensão de um tempo regular, a invenção de outro tempo, seria possível ver como as imagens dessa noite agenciam esse outro tempo? O plano sequência, essa unidade da linguagem cinematográfica, se acopla a estas imagens para produzir o agenciamento de uma outra temporalidade?

\section{Plano Sequência}

Aconteceu alguma coisa naquela noite no Leblon, quem empunhou esta câmera imaginou que palavras por si só não diriam muito, nem depoimentos, nem uma narração, a materialidade do relato precisava ser essa, do movimento pelas ruas, do tempo, da sucessão de fogos que irrompem na imagem do travelling, plano sequência. Não é só o gesto do câmera que produz a relação do plano com o cinema, as próprias ruas clamam por essa imagem e o "mundo se põe 'a fazer cinema"” (DELEUZE, 2008, p. 83). Nesta noite surgem inúmeros planos sequência de diversas naturezas, em especial a partir da mídia ativista, coletivos e realizados por transeuntes anônimos. ${ }^{4}$ Não haveria nessa coincidência estética o próprio acontecimento propondo uma relação com o cinema? Este gesto do plano sequência não se torna parte constituinte da experiência do acontecimento? Se há uma outra experiência temporal sendo engendrada nas jornadas de junho, não estaria ela presente no próprio corpo das imagens?

Seguindo a pista de Escorel, deveríamos olhar um pouco para o cinema ao olhar as imagens desta noite no Leblon. Bazin (1999) apontava para a importância do plano sequência na constituição de uma linguagem do neo-realismo italiano. Mais do que uma descrição e um

\footnotetext{
${ }^{4}$ Outros planos sequência gravados na noite do dia 17 de julho de 2013 podem ser vistos nos seguintes links: <https://www.youtube.com/watch? $\mathrm{v}=8 \mathrm{kljQwNGE-U}>$, $<$ https://www.youtube.com/watch? $=$ =uxq1SAXU22I $>,<$ https://www.youtube.com/ watch?v=nklg_gRcPT0, https://www.youtube.com/watch?v=qTA-zNwURYs $>$. Acesso em: out. 2017.
} 
relato da Europa nos escombros do pós-guerra, o cinema neo-realista propunha uma mirada, um encontro da câmera com o mundo tentando tornar imagem aquilo que não cabia mais nos códigos tradicionais da representação. Como afirma Deleuze a partir de Bazin, "em vez de representar um real já decifrado, o neo-realismo visava um real, sempre ambíguo, a ser decifrado; por isso o plano-sequência tendia a substituir a montagem das representações." (2009, p. 1). Nesse sentido, uma série de personagens perambulam incertos por um mundo que se tornou insuportável e incompreensível, não mais passível de caber no cenário do estúdio, nos artifícios da trama, na unidade teleológica e sim na imagem lacunar, fragmentária e oscilante dos infindos encontros da câmera com o mundo. O filme, seus sentidos, passam a acontecer na sucessão de imagens em relação consigo mesmas e com o mundo, não mais ordenados a partir de uma trama que perpassa a ação dos personagens, como afirma Bazin (1999) a respeito de Paisá (Rosselini, Itália, 1946),

A unidade do relato cinematográfico em Paisá não é o 'plano', ponto de vista abstrato sobre a realidade que se analisa, mas o 'fato'. Fragmento de realidade bruta, por si só múltiplo e equívoco, cujo ‘sentido' se sobressai somente a posteriori, graças a outros 'fatos' entre os quais a mente estabelece relações. (BAZIN, 1999, p. 253)

O plano sequência se vincula, portanto, a uma produção mais intensa de realidade, um "mais de realidade" dirá Deleuze (2009, p. 1), mas que está conectado à experiência de uma realidade intensificada, que não cabe por completo nas histórias, mas transborda no plano. O mundo não precisa caber por inteiro na imagem, basta que este insuportável ou esta dúvida sobre o mundo apareça de alguma forma. O que Bazin nos indica é que para além do contexto, da dureza da paisagem e das vidas do pós-guerra, há uma dimensão estética na forma de registrar esta experiência que se pode chamar neo-realismo. O plano sequência é parte dos esforços dessa linguagem de aderência e produção de uma realidade na imagem, é um gesto político que aponta para o tempo, a duração do plano, "Trata-se ali de tornar espetacular e dramático o próprio tempo da vida, a duração natural de um ser a quem nada de particular acontece" (BAZIN, 1999, p. 291). Ao invés de um cinema da supressão do tempo, da estrutura lógica das elipses, teríamos um cinema das ações banais, insignificantes, desenvoltas na "duração" do plano, 
Assim, a unidade-evento num filme clássico seria o 'acordar da empregada': dois ou três planos breves bastariam para significá-lo. A essa unidade do relato De Sica substitui uma sequência de eventos menores: o acordar, a travessia do corredor, a inundação das formigas etc. (BAZIN, 1999, p. 298)

Mas, não estamos na Itália do pós-guerra e sim no Rio de Janeiro de hoje, se por um lado há um extraordinário, a insurgência nas ruas, as câmeras e seus planos sequência não apontam para o banal e insignificante. $\mathrm{O}$ foco destas imagens é justamente o gesto insurgente, as chamas que tomam conta da rua, é a tentativa de fazer este gesto habitar a tela ou a experiência das ruas se fazer presente na imagem. Ainda que na duração destes planos haja espaço para tempos mortos e para a não ação. Não se trata apenas de imagens retratando conflitos e explosões ininterruptas, como o próprio plano "Leblon em Chamas" mostra nos seus quase três minutos em que a ação preponderante é o queimar das chamas e a câmera que se desloca. No entanto, a aproximação com o plano sequência de Bazin se dá, primeiramente, pela intensidade de um real a partir de um "insuportável" que não é o gesto em si, a tomada das ruas, mas o que provoca a revolta, a precariedade das vidas na cidade. $\mathrm{O}$ cinema aparece como gesto, como olhar, nessa intensidade e nesse vínculo inexorável com o real, despido da representação como paradigma. Aqui a imagem, como nos exemplos de Bazin, busca a experiência inexplicável de se estar nas ruas na turbulência daquele momento.

\section{Contiguidade e simultaneidade}

Estes planos sequência, diante da natureza dos protestos e sua coexistência entre as ruas e as telas, estabelecem uma relação de contiguidade e simultaneidade com os manifestantes nas ruas. A dimensão espacial e da ação naquele espaço da cidade, as barricadas em chamas em cada cruzamento, constituem a força desestabilizadora do protesto. O que seria desta potência insurgente sem sua dimensão imagética capaz de revelar aos nossos olhos sua ocupação se desdobrando no espaço? E o que seria desta dimensão espacial sem a duração e a temporalidade do plano sequência? Se a forma de ocupação espacial do protesto, em especial nessa noite no Leblon, é parte constitutiva de sua potência política, o plano sequência como linguagem, surge como parte constitutiva desta força. 
Há o gesto inaugural das ruas em que os corpos aleatoriamente ocupam a extensão das ruas do Leblon até Ipanema e há o plano sequência que incorpora na contiguidade da sua natureza a dimensão espacial do gesto que é parte de sua potência. Os planos sequência que aparecem desta noite, alguns como o caso do "Leblon em Chamas", são divulgados na rede em simultâneo ao acontecimento, existem a partir das ruas, mas constituem ao mesmo tempo sua potência. Presente intenso e intensificado pelo gesto cinematográfico em meio a insurgência. A dimensão temporal e espacial destes planos se conecta diretamente com a potência política da multidão das ruas.

Esta relação de contiguidade é mais evidente nas imagens de confrontos diretos com a polícia e de apropriação do espaço, em que um corte quebraria com a relação entre os sujeitos no embate e no espaço da cidade. Há ainda os planos que acompanham prisões, flagrantes e operam como denúncia da ação truculenta da polícia. Nesses casos, a ausência do corte é fundamental para preservar a ação na íntegra e seu grau de veracidade, ainda que, sejam apenas imagens. O plano sequência se vincula aos corpos e vidas que estão diante da câmera, esta aderência ao real e ao mundo que explode diante das câmeras é um apego às vidas que estão em risco. E nesse sentido, diante das vidas e corpos brutalizados pelo Estado, poderíamos até concordar com Bazin que o corte na imagem se torna "proibido", "O que deve ser respeitado é a unidade espacial do acontecimento no momento em que sua ruptura transformaria a realidade em sua mera representação imaginária." (BAZIN, 1999, p. 62). A violência do Estado contra manifestantes pode ser tudo, menos imaginária.

É importante frisar esta potência do plano sequência em dar a ver o acontecimento, mais ainda em colocar em cena o contexto em que a ação acontece. A cidade insurgente é a cidade na possibilidade de transformação, a poética da política se faz nesse devir de tornar as vidas outras, na possibilidade mesmo de mudança. A incidência de tantos planos sequência nesta noite ou mesmo durante toda a turbulência de junho de 2013 seria obra do acaso? Ou faz parte de uma poética insurgente em que os devires se mostram e se conectam com uma estética produzida pelo plano sequência, no qual a contiguidade faz parte da sua natureza?

Há evidentes transformações ou rupturas simbólicas postas em cena e performadas diante de planos sequência como o momento em que manifestantes depredam a fachada do edifício da Rede Globo de 
Televisão no Leblon. ${ }^{5}$ Aqui é fundamental acompanhar toda a ação que começa com a multidão entoando - "a verdade é dura a rede Globo apoiou a ditadura" e passa para a os manifestantes quebrando a porta de vidro da entrada e colocando fogo em pedaços de papelão fazendo muita fumaça. O plano encerra com o batalhão de fotógrafos registrando os escombros da fachada já sem a presença de qualquer manifestante, apenas o depois da destruição sem o ato em si, sem os aplausos quando a porta se quebra, sem a euforia da multidão, sem os olhares dos funcionários acuados nas janelas ou dos seguranças receosos no saguão de entrada. Há toda a passagem da fachada com seu impecável vidro fumê para os destroços e os funcionários acuados, mal ou bem, há a transformação material do edifício, como da euforia e potência dos manifestantes durante o gesto destrutivo. A Rede Globo não é qualquer canal midiático, mas o canal hegemônico que construiu seu império durante a ditadura de 1964 apoiando o governo militar e que durante os protestos se colocou, a princípio, contra os manifestantes, contra os "vândalos". Faz todo o sentido os aplausos eufóricos da multidão quando a porta de vidro se espatifa.

Na mesma noite, em outro ponto do Leblon, na Ataulfo de Paiva um homem faz um registro ainda mais radical, da perspectiva estética de uma invenção, de um inexplicável que irrompe da insurgência. No vídeo sem descrição intitulado Leblon 2 postado no dia 18 de julho de 2013, um dia após os protestos, o plano começa com uma barricada em chamas ao longe e logo vemos um grupo de pessoas que passa pela barricada em direção à câmera. ${ }^{6} \mathrm{O}$ grupo caminha como se estivesse em uma procissão, são jovens, cantam como se fossem um coral em loop "paz, paz, paz, na terra, no céu e no mar, paz, paz, paz, fez o senhor da paz", e vagarosamente seguem pela rua e suas barricadas em chamas. Um transeunte interpela o câmera se ele sabe quem são eles, "é um grupo religioso?" pergunta, o câmera não sabe, não tem a menor ideia quem são, mas continua filmando. A "procissão" cruza os dois e desce a rua com suas infindas barricadas em chamas, um skatista atravessa o quadro ziguezagueando as fogueiras, vai no rumo da "procissão" enquanto câmera e transeunte passam a discutir política fora do quadro. Mais para

\footnotetext{
${ }^{5}$ Disponível em: $<$ https://www.youtube.com/watch?v=qTA-zNwURYs $>$. Acesso em: out. 2017.

${ }^{6}$ Disponível em: $<$ https://www.youtube.com/watch? $\mathrm{v}=\mathrm{m} 9 \mathrm{CFODWjnEI}>$. Acesso em: out. 2017.
} 
o final do plano diante da cantoria que se esvai e dos fogos que insistem em queimar, os dois estranhos concordam que "nunca haviam visto isso antes, não aqui, no Leblon, na Ataulfo de Paiva".

A cena inesperada e "incrível" nas palavras de quem está filmando é tributária de todo o contexto da noite, do protesto, do gesto do grupo que segue em procissão e das chamas das inúmeras barricadas que se espalham pelas ruas do Leblon. Todos estes fragmentos fazem parte de uma mesma cena e a unidade deste gesto, que depende de todo esse conjunto, se mantém no plano sequência. A potência desta imagem depende não só dos manifestantes e de suas ações no bairro, mas do plano sem cortes que não só atomiza a potência política dessas ações, mas produz uma experiência da ação no tempo, no tempo da insurgência.

\section{Mais uma vez o fogo}

Hoje, quatro anos após as jornadas de junho, falar em revolta, da rua tomada de corpos, de uma multidão que grita, arde, deseja, é parecer deslocado do tempo, como se não falasse mais do presente. Afinal, o que sucedeu junho foi um recrudescimento de um pensamento conservador, o impeachment da presidenta Dilma e uma radicalização de políticas econômicas neoliberais. Nada mais distante da chama que se ascendeu durante os protestos. Querem nos fazer crer que vivemos em um beco sem saída. Que há uma crise incontornável, sem solução a não ser a austeridade, a expropriação contínua. Mas, se de fato vivemos em um tempo de emergência, quando foi que vivemos fora dele?

Guattari em um texto de 1984 sobre o papel das esquerdas após as recentes eleições na França diz - "E o que resulta é: um comparecimento as urnas consideravelmente baixo no 17 de junho; o fascismo constituindo por si só uma força; a dissolução da capacidade coletiva em resistir ao conservadorismo; o crescimento do racismo e uma inércia petrificante." (GUATTARI, 1996, p. 1). ${ }^{7}$ Mas, podemos recuar à década anterior ao ano de 1974 em que, como nos informa Didi-Huberman, Pasolini desenvolve sua ideia de "genocídio cultural" no qual o fascismo, "é aquele que tem por alvo os valores, as almas, as linguagens, os gestos,

\footnotetext{
${ }^{7}$ Tradução livre de "And what result is this: a significantly low voter turn-out on June 17; Fascism constituting itself as a force; the frittering away of the collective capacity to resist conservatism; the rise of racism and a stony inertia". (GUATTARI, 1996, p. 1)
} 
os corpos do povo. É aquele que conduz sem carrascos nem execuções em massa, à supressão de grande porções da própria sociedade." (DIDIHUBERMAN, 2011, p. 29). O que Pasolini quer dizer é que apesar dos fascistas terem sido derrotados na guerra, um modo vida burguês que anula todas as singularidades havia, naquele momento, triunfado na Itália. Se dermos mais um salto para trás, um salto histórico a moda de Benjamin, podemos olhar para a sua afirmação, já clássica, de que - "Nunca houve um monumento da cultura que não fosse também um monumento da barbárie" (BENJAMIN, 2008, p. 225). Quando foi que o fascismo, a violência, a barbárie não estiveram à espreita? Não poderíamos dizer o mesmo sobre a revolta? Quando foi que o risco de sublevação não estivesse à espreita?

Nesse sentido, vale a lição Benjaminiana no exercício de olhar estas imagens, não pelo prisma da derrota, mas pelas forças políticas e subjetivas que permanecem, da possibilidade da revolta se erguer novamente no presente e o incêndio mais uma vez tomar as ruas. Não estamos no tempo da sucessão e uma vez que houve produção subjetiva e política durante as jornadas de junho, ela não se dissipa simplesmente, resiste como potência, como aprendizado político, como sintoma de uma luta que não se resolve por completo. Negri (2016), ao comentar a figura do Angelus Novus em Benjamin, nos diz que sua força não aponta para o passado, mas para o presente e na possibilidade constante das atualizações das lutas, da revolução que "ainda não" se fez presente, de como olhar a história é olhar um presente não apaziguado formado por camadas e camadas de conflitos,

O Angelus Novus não é uma teologia do passado, mas uma ontologia do presente, do ainda não. Há um certo treinamento secular que leva multidões a abalar os limites do poder com uma força crescente. As derrotas são um estrato, um depósito, um que é vivo. Não são inertes, são paixões que continuam produzindo subjetividade, produção que não pode ser interrompida. A derrota também é a indicação de uma força subterrânea sempre capaz de sublevar-se à superfície. (NEGRI, 2016, p. 42) ${ }^{8}$

\footnotetext{
${ }^{8}$ Tradução livre de "The Angelus Novus is not a theology of the past, but an ontology of the present, of the not-yet. There is a sort of secular training that leads the multitudes to shake the limits of power with growing force. The defeats are a stratum, a deposit,
} 
Devemos, portanto, mais uma vez olhar o fogo. A performance dos manifestantes nas ruas na noite do 17 de julho de 2013 produziu inúmeras chamas que também vieram a povoar inúmeras imagens. Bachelard já nos alertava sobre o poder da chama em produzir imagens, mas não só isso, em produzir fantasias, "A chama, dentre os objetos do mundo que nos fazem sonhar, é um dos maiores operadores de imagens. Ela nos força a imaginar. Diante dela, desde que se sonhe, o que se percebe não é nada, comparado com o que se imagina." (BACHELARD, 1989, p. 9). Safatle (2016) tinha razão ao propor que olhemos o fogo que queima nas ruas. $\mathrm{O}$ que estas imagens produzem aqui e agora, vistas e revistas após o acontecimento no dispositivo das redes, são as chamas nas ruas, que não apenas queimam, consomem, impedem o fluxo do trânsito, mas inventam imagens, terríveis e belas, da luta, da resistência e mais do que tudo, fantasiam outros sujeitos e outras cidades.

\section{Referências}

BACHELARD, Gaston. A chama de uma vela. Rio de Janeiro: Editora Bertrand Brasil, 1989.

BAZIN, André. O Cinema: ensaios. São Paulo: Editora Brasiliense, 1991.

BENJAMIN, Walter. Obras escolhidas. v 1: Magia e técnica, arte e política. São Paulo: Brasiliense, 2008.

DELEUZE, Gilles. Conversações. São Paulo: Editora 34, 2008.

DELEUZE, Gilles. A imagem-tempo. São Paulo: Editora Brasiliense, 2009.

DIDI-HUBERMAN, Georges. Sobrevivência dos vaga-lumes. Belo Horizonte: Editora UFMG, 2011.

GAGNEBIN, Jeanne Marie. História e narração em Walter Benjamin. São Paulo: Perspectiva, 1999.

GUATTARI, Félix. Left as processual passion. In: GENOSKO, Gary. The Guattari reader. Oxford: Blackwell, 1996.

and a living one. They are not inert, they are passions that keep producing subjectivity, production that cannot be stopped. Defeat is also an indication of a subterranean power always capable of rising up to the surface." (NEGRI, 2016, p. 42) 
NEGRI, Antonio. Uprising as an event. In: DIDI-HUBERMAN, Georges. Uprisings. Paris: Gallimard; Jeau de Paume, 2016.

PALBERT, Peter Pál. A terra a guerra e a insurreição. Revista Ecopós, v. 18, n. 2, p. 161-170, 2015.

RANCIERE, Jaques. One uprising can hide another. In: DIDIHUBERMAN, Georges. Uprisings. Paris: Gallimard; Jeau de Paume, 2016.

SAFATLE, Vladimir. Quando as ruas queimam: manifesto pela emergência. São Paulo: N-1 Edições, 2016. 